\title{
No interaction between serotonin transporter gene (5-HTTLPR) polymorphism and adversity on depression among Japanese children and adolescents
}

\author{
Akemi Tomoda ${ }^{1 *}$, Shota Nishitani ${ }^{2}$, Naomi Matsuura ${ }^{3}$, Takashi X Fujisawa ${ }^{1,2}$, Junko Kawatani ${ }^{4}$, Daiki Toyohisa ${ }^{4}$, \\ Mai Ono ${ }^{4}$ and Kazuyuki Shinohara ${ }^{2}$
}

\begin{abstract}
Background: Identification of gene $\times$ environment interactions $(G \times E)$ for depression is a crucial step in ascertaining the mechanisms underpinning the disorder. Earlier studies have indicated strong genetic influences and numerous environmental risk factors. In relation to childhood and adolescent depression, evidence is accumulating that the quality of the parental environment is associated with serotonin biology in children. We hypothesized that maternal depression is a crucial environmental risk factor associated with serotonin-regulating genes.
\end{abstract}

Methods: This study was designed to ascertain the $G \times E$ interaction for diagnosis of depression in a Japanese pediatric sample. DNA samples from 55 pediatric patients with depression and 58 healthy schoolchildren were genotyped for the 5-HTT (2 short (S) alleles at the 5-HTT locus) promoter serotonin-transporter-linked polymorphic region (5-HTTLPR) polymorphism. We examined whether an adverse parental environment, operationalized as the mother's history of recurrent major depressive disorder, interacts with 5-HTTLPR polymorphism to predict patients' depression symptoms.

Results: Binary logistic regression analyses revealed that maternal depression (adversity), gender, and FSIQ significantly affect the diagnosis of depression among children and adolescents. However, no main effect was found for adversity or genotype. Results of multivariable logistic regression analyses using stepwise procedure have elicited some models with a good fit index, which also suggests no interaction between 5-HTTLPR and adversity on depression.

Conclusions: To assess $\mathrm{G} \times \mathrm{E}$ interaction, data obtained from children and adolescents who had been carefully diagnosed categorically and data from age-matched controls were analyzed using logistic regression. Despite an equivocal interaction effect, adversity and gender showed significant main effects.

Keywords: Child depression, Gene-by-environment $(G \times E)$ interaction, Serotonin transporter gene (5-HTTLPR) Polymorphism, Early adversity

\section{Background}

Depression, an etiologically heterogeneous group of brain disorders characterized by widely various symptoms that reflect altered cognitive, psychomotor, and emotional processes $[1,2]$, strongly affects $3-5 \%$ of children and adolescents [3]. Depression negatively impacts growth and development, school performance, and peer or family

\footnotetext{
* Correspondence: atomoda@u-fukui.ac.jp

'Research Center for Child Mental Development, University of Fukui, Fukui, Japan

Full list of author information is available at the end of the article
}

relationships; it can lead to suicide [4-6]. Biomedical and psychosocial risk factors include a family history of depression, female sex, childhood abuse or neglect, stressful life events, and chronic illness $[3,7,8]$. Previous results of studies suggest that exposure to childhood adversity is associated with depression symptoms [9-12]. Although people at risk tend to have poor life outcomes, some people do well despite adversity. Protective factors such as good intellectual skills, positive temperament, parental warmth, parental involvement, and strong social connections are believed to play an important role in protecting 
individuals from poor development, psychological problems, and mental illness from the viewpoint of genetic etiology [13].

Results of previous studies suggest that homozygous carriers of the short allele $(S / S)$ of the serotonin transporter gene-linked polymorphic region (5-HTTLPR) might be at increased risk for depression if they have also been exposed to early or current adversity or stress [14].

A growing body of evidence suggests that 5-HTTLPR interacts with adverse environmental influences to produce increased risk for the development of depression, although the underlying mechanisms of this association remain largely unexplored [15-19]. Various reports have described that 5-HTTLPR genotype moderates the relation between stress and depression and interacts to contribute to risk for depression in children [20-22]. However, recent metaanalyses have produced no evidence that the 5-HTTLPR genotype alone or in interaction with stressful life events is associated with an elevated risk of depression [23], or that the main effect of 5-HTTLPR genotype and the interaction effect between 5-HTTLPR and stressful life events on risk of depression are negligible [24]. Therefore, we should conduct an examination to incorporate consideration of the possibility of other confounding variables such as gender, age, and socioeconomic status along with stressful life events.

Research in this area can recast our thinking about the role of early experience in psychopathology and genetic interaction. Considering previous research, we hypothesized that interaction between 5-HTTLPR and early adversity is involved in the etiology of childhood depression. No study has tested Japanese children and adolescents. Therefore, the aim of this study is to examine whether opposite $\mathrm{G}$ (5-HTTLPR genotype) $\times \mathrm{E}$ (maternal depression) interactions can be confirmed among Japanese children and adolescents. Our additional research findings will contribute to the resolution of inconsistencies in the literature. One principle aim in the current study was to test whether opposite gene-by-environment $(\mathrm{G} \times \mathrm{E})$ interactions with maternal depression can be found for Japanese children and adolescents with childhood depression. This study examined $\mathrm{G} \times \mathrm{E}$ interactions in a sample of children with Japanese pediatric depression to test the hypothesis that 5-HTTLPR is involved in the etiology of childhood depression.

\section{Methods}

\section{Ethics statement}

The Committee of Life Ethics, Graduate School of Medicine, Kumamoto University approved the study protocol, Assurance \# KUM0313. During the review of this Project, the committee specifically considered (i) the risks and anticipated benefits, if any, to subjects; (ii) the selection of subjects; (iii) the procedures for securing and documenting informed consent; (iv) the safety of subjects; and (v) the privacy of subjects and confidentiality of the data. All potential participants who declined to participate or otherwise did not participate were eligible for treatment (if applicable) and were not disadvantaged in any other way by not participating in the study. According to the Declaration of Helsinki, parents or guardians of all participants provided written informed consent for children to participate in the study after the study procedures had been explained to them.

\section{Subjects}

This study examined 55 unmedicated patients with depression: 21 boys and 34 girls aged 8-16 years (mean age, 14.3 years; standard deviation [SD], 1.9 years) who were referred to our laboratory during 2007-2011 for examination of depression (Table 1). All the patients were referred from their private pediatric clinics. For that reason, there might be referral bias related to severity despite the drug-naïve condition used for this study. All patients satisfied diagnostic criteria for depression of the Diagnostic and Statistical Manual of Mental Disorders, Fourth Edition, Text Revision (DSM-IV-TR) (American Psychiatric Association, 2000) [2]. To exclude other psychiatric diagnoses, the Mini-International Neuropsychiatric Interview for Children and Adolescents (MINI Kids) was administered by a licensed pediatric-psychiatric clinician. The patient group did not have high levels of suicidality or comorbidity.

To obtain data from normal age-matched healthy controls (HC), healthy schoolchildren and adolescents aged 8-16 years were recruited as subjects from the community; school students were targeted. The control group comprised 40 boys and 18 girls (mean age, 13.8 years; SD, 2.1 years). None had below-average IQ, physical problems, or psychiatric psychopathology.

All participants' race/ethnicity was Japanese. Patients who had undergone treatment with antidepressants or hypotension drugs, or who had diagnoses of neurological illness, migraine, obstructive sleep apnea, below average IQ, or severe psychopathology were excluded from the study. Severe psychopathology was evaluated by referral to at least one pediatric psychiatrist if the patient presented indicative symptoms.

No control subject had any history of DSM-IV-TR Axis I Disorder (based on MINI Kids) including attention deficit hyperactivity disorder (ADHD) or other pervasive developmental disorder, or any history of any form of abuse or drug abuse. Table 1 presents clinical characteristics of the subjects.

As an adult control reference, we also used commercially supplied DNA of Japanese adult subjects (age 44.26 \pm 13.58, 50 male and 50 female) supplied by the Health Science Research Resources Bank, Osaka, Japan. 
Table 1 Demographics, early adversity, and clinical characteristics in individuals in patients and healthy controls

\begin{tabular}{|c|c|c|c|c|}
\hline & $\begin{array}{l}\text { Healthy controls } \\
\qquad(n=58)\end{array}$ & $\begin{array}{l}\text { Patients } \\
(n=55)\end{array}$ & $\begin{array}{c}\text { t-test, ANOVA, other } \\
t(F) \text {-value }\end{array}$ & P-value \\
\hline \multicolumn{5}{|l|}{ Demographics } \\
\hline Age (years) & $13.8 \pm 2.1$ & $14.3 \pm 1.9$ & 1.21 & 0.4 \\
\hline Gender (Males/Females) & $40 \mathrm{M} / 18 \mathrm{~F}$ & $21 \mathrm{M} / 34 \mathrm{~F}$ & Fisher Exact & 0.01 \\
\hline Early Adversity & 0 & 11 & Fisher Exact & $<0.001$ \\
\hline Socioeconomic Status & $4.1 \pm 0.6$ & $4.0 \pm 0.7$ & 2.62 & 0.11 \\
\hline \multicolumn{5}{|l|}{ Clinical Characteristics } \\
\hline SDS Score* & $36.47 \pm 6.19$ & $56.95 \pm 6.42$ & $(-235.96)$ & $<0.001$ \\
\hline DSRS-C Score* & $7.51 \pm 4.33$ & $21.92 \pm 6.23$ & $(189.03)$ & $<0.001$ \\
\hline Full Scale IQ* & $109.56 \pm 12.15$ & $94.29 \pm 16.49$ & -6.43 & 0.01 \\
\hline Verbal IQ* & $105.74 \pm 9.92$ & $89.24 \pm 17.37$ & -9.44 & 0 \\
\hline Performance IQ* & $108.74 \pm 10.69$ & $95.78 \pm 15.60$ & 7.67 & 0.01 \\
\hline Verbal Comprehension Index* & $109.12 \pm 13.00$ & $92.38 \pm 22.08$ & 9.05 & 0 \\
\hline Perceptual Organization* & $104.41 \pm 11.98$ & $88.90 \pm 21.67$ & 4.2 & 0.04 \\
\hline Freedom from Distractibility* & $107.35 \pm 12.39$ & $91.7 \pm 22.36$ & 3.27 & 0.08 \\
\hline Processing Speed Index* & $109.06 \pm 10.50$ & $89.92 \pm 25.61$ & 7.99 & 0.01 \\
\hline Youth Self Report Score (total) & $53.9 \pm 25.5$ & $84.5 \pm 35.9$ & 23.59 & $<0.001$ \\
\hline Youth Self Report Score (internal) & $8.3 \pm 7.2$ & $25.1 \pm 8.3$ & 63.91 & $<0.001$ \\
\hline Youth Self Report Score (external) & $10.2 \pm 6.7$ & $14.1 \pm 8.6$ & 5.46 & 0.02 \\
\hline
\end{tabular}

* ANCOVA with age and gender as covariates. Values are presented as the mean and SD.

DSRS-C, Birleson Depression Self-Rating Scale for Children.

\section{Assessments}

\section{Depression scales}

The severity of depressive symptoms was measured using the Zung self-rating depression scale (SDS) and the Birleson Depression Self-Rating Scale for Children (DSRS-C), which are similar to the children's depression inventory used in pediatric psychiatry. The validity and reliability of Japanese version of these scales were confirmed $[25,26]$. Methods used for these analyses were described previously [27].

\section{Wechsler Intelligence Scale for Children-Third Edition (WISC-III)} An individually administered measure of intelligence intended for children aged 6 years to 16 years and 11 months, WISC-III, was administered by a licensed pediatric-psychological clinician to estimate intellectual capacity [28]. The version is applicable to Japanese children and adolescents.

Child Behavior Checklist Youth Self-Report (CBCL-YSR) and SES Patients with child depression had mean scores of 25 and 14, respectively, for Internalizing and Externalizing Problems on the CBCL Youth Self-Report [29].

Low income and poverty might be important developmental risk factors related to psychopathology [30]. The parental socioeconomic status (SES) test was administered as a composite measure of socioeconomic status [31,32].
Socioeconomic status was classified as follows: annual income below 2 million yen, 1 ; 2-4 million yen, 2; 4-6 million yen, 3; between 6 and 8 million yen, 4, 8-10 million yen, 5 ; 10-12 million yen, 6 ; more than 12 million yen, 7 .

\section{Early adversity}

The patients' mothers were also administered a clinical interview by a specialized physician, the Structured Clinical Interview for the DSM-IV (SCID), to assess their Axis-I disorders. They were investigated if they had either (1) no current/past disorder (low early adversity); or (2) at least two major depressive episodes during their children's lifetime but were currently in remission (high early adversity). Approximately $20 \%(n=11)$ of the mothers had recurrent depression; the remaining $80 \%(n=44)$ had no history of mental health disorders. No control subject's mother had high early adversity. Selected from the same community sample, control subjects' mothers with no history of psychiatric problems or exposure to traumatic events served as a no early adversity contrast group.

\section{Genotyping}

Genomic DNA was extracted directly from blood samples of patients using standard techniques (MagNa pure LC350; Roche Diagnostics Corp.). In control subjects, we used a mouth swab sampling technique and extracted the DNA from buccal cells using a standard commercial extraction 
kit QIAamp DNA Micro Kit (Qiagen Inc., Tokyo, Japan). This study was conducted with ethnically homogeneous individuals (all were of Japanese descent) [33].

The serotonin transporter gene (5-HTTLPR) of the 5HTT gene regulatory region was amplified by polymerase chain reaction (PCR) with forward primer (5'-GGCGTT GCCGCTCTGAATGC-3') and reverse primer (5'-GAGG GACTGAGCTGGACAACCAC-3'). For PCR, $10 \mathrm{ng}$ of genomic DNA was used in a $25-\mu \mathrm{L}$ reaction mixture containing $0.5 \mathrm{U}$ of KOD FX Neo (Toyobo Co. Ltd.) and 10 pmol of each primer in PCR buffer for KOD FX Neo (Toyobo Co. Ltd.). Cycling conditions were the following: denaturation $\left(94^{\circ} \mathrm{C}\right.$ for $\left.2 \mathrm{~min}\right)$ and 30 cycles of amplification $\left(98^{\circ} \mathrm{C}\right.$ for $10 \mathrm{~s}, 63^{\circ} \mathrm{C}$ for $30 \mathrm{~s}$ and $68^{\circ} \mathrm{C}$ for $\left.30 \mathrm{~s}\right)$. The PCR products were separated using electrophoresis in a $3 \%$ agarose gel and visualized by UV after ethidium bromide staining. A 484 bp band was observed for the short (S) allele, and a 528 bp band for the long (L) allele; heterozygous samples showed both the alleles. Two investigators scored allele sizes independently. Any inconsistency was reviewed and procedures were repeated if necessary. Genotyping was conducted blindly without knowledge of the clinical information.

The PCR-based analyses revealed that the distribution of allele frequency in the patients was $76 \%$ for the S-allele and $24 \%$ for the L-allele (Table 2). The distribution of the S/S, $\mathrm{S} / \mathrm{L}$, and $\mathrm{L} / \mathrm{L}$ genotypes was, respectively, $60 \%(n=33), 33 \%$ $(n=18)$, and $3 \%(n=7)$. In the Japanese population, LL type of 5-HTTLPR has been reported as rare. Therefore, it might be better to examine the 5-HTTLPR proportion using Fisher's exact test or MCMC. However, some previous reports have described the use of Hardy-Weinberg equilibrium examination empirically $[34,35]$. We also administered Hardy-Weinberg equilibrium examination. The observed genotype distribution was similar to the expected HardyWeinberg equilibrium distribution. The genotypes were divided into $\mathrm{S} / \mathrm{S}$ and $\mathrm{S} / \mathrm{L}+\mathrm{L} / \mathrm{L}$ genotypes because only four subjects with the L/L genotype were found in our sample. This genotype is uncommon among Japanese people [36].

\section{Data analysis}

The clinical variables were compared in both groups using $t$-tests for quantitative data and Fisher exact tests for qualitative data. Data are expressed as the mean \pm SD. To explore the relation between depressive symptoms and the genotypes of the 5-HTTLPR polymorphism, analysis of covariance (ANCOVA) was performed for each of the depression scores (total SDS and DSRS-C scores) using age and gender as covariates because it has been suggested that a variable such as age might affect responses to the depression rating [30]. To confirm the main effect on the diagnosis of depression, we used binary logistic regression and set genetic, environmental factors, and the effect of the interactions between 5-HTTLPR genotype and adversity as independent variables.

Next, multivariable logistic regression analyses were performed. The dependent variable was the status of diagnosis $(0=$ no diagnosis, $1=$ diagnosed as depression). All predictor variables were entered simultaneously into the model. Some possible models were conducted using stepwise procedures. Finally, two-way analysis of variance (ANOVA) was conducted to assess the effect of $\mathrm{G} \times \mathrm{E}$ interaction in each genotype group.

All statistical tests ( $t$-test, ANCOVA and Fisher exact test, logistic regression analyses, and two-way ANOVA for discrete variables) were two-sided; $P$ values less than .05 were inferred as statistically significant. Statistical analyses were conducted using software (SPSS Statistics 20; SPSS Inc., Chicago, IL).

\section{Results}

\section{Demographics and IQ}

Table 1 shows that the patient and control groups were well matched in terms of age $(F=1.21, P=0.40)$ and SES $(F=$ $2.62, P=0.11)$. Female predominance was found in the patient group (Fisher exact, $P=0.008$ ). Subjects in the patient group were predominantly male (69\%), whereas controls were predominantly female (61\%; Table 1). Of 55 children and adolescents in the patient group, 11 had early adversity, although none had it in the $\mathrm{HC}$ group. As expected, the patient group had high SDS scores with a mean of $57.0 \pm 6.4$ $(F=235.96, P<0.001)$ and high DSRS-C scores with a mean of $21.9 \pm 6.2(F=189.03, P<0.001)$. In addition, those who were diagnosed as having depression had a significantly higher total score of CBCL-YSR $(F=23.59, P<0.001)$ and internalizing score of that $(F=63.91, P<0.001)$ than those of the $\mathrm{HC}$ group.

The patient group had significantly lower full-scale IQ (FSIQ) without discrepancies between verbal IQ (VIQ) and performance IQ (PIQ), compared to the HC group

Table 2 5-HTTLPR genotype distributions and allele frequencies in controls and depressive patients

\begin{tabular}{|c|c|c|c|c|c|}
\hline & \multicolumn{3}{|c|}{ Genotypes, n (\%) } & \multicolumn{2}{|c|}{ Allele frequencies, $\mathrm{n}(\%)$} \\
\hline & $\mathrm{S} / \mathrm{S}$ & S/L & L/L & $S$ & $\mathbf{L}$ \\
\hline Patients & $33(60.0)$ & $18(32.7)$ & $4(7.3)$ & $84(76.4)$ & $26(23.6)$ \\
\hline Age-matched Controls & $32(62.7)$ & $16(31.4)$ & $3(5.9)$ & $80(78.4)$ & $32(21.6)$ \\
\hline Adult Controls & $51(51.0)$ & $47(47.0)$ & $2(2.0)$ & $149(74.5)$ & $51(25.5)$ \\
\hline
\end{tabular}


$(94.3 \pm 16.5$ vs. $109.6 \pm 12.2)(F=6.43, P=0.013$; Table 1$)$. Similarly, VIQ and PIQ showed significant differences in scores between the two groups (VIQ, $F=9.44, P=0.003$; PIQ, $F=7.67, P=0.007$ ).

The genotypic and allelic frequencies of the 5-HTTLPR variants are presented in Table 2 . The distribution of allelic frequency of the patients and age-matched controls was found to be almost identical to that previously reported in Japanese people, exhibiting a similar tendency to that of our Japanese adult sample (frequency for the L/L, S/L, and S/S genotypes was: 7,33 , and $60 \%$ in the patients and 6 , 31 , and $63 \%$ in the age-matched controls, respectively). The overall pattern of results derived by genetic studies of 5-HTTLPR is most suggestive for a dominant mode of action of the S allele [37]. We therefore analyzed S/L heterozygous patients grouped with $\mathrm{L} / \mathrm{L}$ homozygous patients (i.e., $L / L+S / L$ versus $S / S$ ). No significant difference was found in the genotypic or allelic frequencies of 5-HTTLPR between both groups, suggesting that no sampling bias exists in the study.

As shown Table 1, significant differences were found between two groups in FSIQ, depression scores, and scores of CBCL. Because of the significant main effects of FSIQ and gender, we assumed that interaction effects between variables such as $\mathrm{SES} \times$ age, $\mathrm{SES} \times \mathrm{FSIQ}$, and gender $\times$ age would be large.

\section{Evaluation of binary logistic regression analyses}

In this study, we examined the main effect of diagnosis as depression in childhood and adolescence using binary logistic regression analyses. Adversity, gender, and FSIQ were found to be significantly associated with depression [adversity, $P<0.0001, \quad O R=2129500000$; gender, $P=0.008$, OR $(95 \% \mathrm{CI})=0.345(0.158-0.754)$; FSIQ: $P=0.001$, OR $(95 \% \mathrm{CI})=0.931(00.892-0.971)]$. A significant $\mathrm{G} \times \mathrm{E}$ interaction was observed $(P<0.0001$, $\mathrm{OR}=1142600000)$. However no significant main effect in genotype was found (Table 3).

\section{Evaluation of multivariable logistic regression analyses}

As results of multivariable logistic regression analyses using stepwise procedure, we confirmed three models that have goodness of fit (Table 4). In Model 1, significant effects of $\mathrm{G} \times \mathrm{E}$ interaction, adversity, gender, and SES were found [fitness index of this model: $X^{2}=61.216(P<0.001),-2 \log$ likelihood $=37.706$, discrimination accuracy $=96.9 \%$ ]. In Model 2, the effect of $\mathrm{G} \times \mathrm{E}$ interaction was excluded and the fitness index of the model was changed [fitness index of this model, $X^{2}=61.216(P<0.001),-2 \log$ likelihood $=$ 37.706, discrimination accuracy $=96.9 \%]$. Finally, Model 3, the simplest, was inferred when all variables were used simultaneously in the analyses. A significant main effect of gender and FSIQ was found [fitness index of this model,
$X^{2}=50.660(P<0.001),-2 \log$ likelihood $=48.262$, discrimination accuracy $=96.9 \%]$.

We conducted two-way ANOVA to examine the main and confounding effects on DSRS-C score in all participants. No significant $\mathrm{G} \times \mathrm{E}$ interaction between 5-HTTLPR genotype and adversity or main effects of genotype, adversity, and gender was found from these analyses (Table 5). Additionally, the mean scores of DSRS-C in each genotype group were analyzed. No significant difference was found in any group.

\section{Discussion}

Interaction between adverse parental environment and gender showed a significant main effect despite a lack of $\mathrm{G} \times \mathrm{E}$ interaction in a Japanese pediatric sample. Because all participants in this study were ethnically homogenous, this is an important consideration for generalizing the present findings.

Depression is a critical and common condition found in children and adolescents as well as adults [3,38-40].

Table 3 Binary logistic regression analyses for variables of genotype, adversity, gender, age, SES, FSIQ, and Genotype (G) $\times$ Environment (E)

\begin{tabular}{|c|c|c|c|c|c|}
\hline \multicolumn{6}{|c|}{ Genotype (G) } \\
\hline B & SE & Wald & $p$ value & OR & $95 \% \mathrm{Cl}$ \\
\hline 0.11 & 0.32 & 0.119 & 0.730 & 1.12 & $0.600-2.073$ \\
\hline \multicolumn{6}{|c|}{ Adversity (E) } \\
\hline B & SE & Wald & $p$ value & OR & $95 \% \mathrm{Cl}$ \\
\hline 21.48 & 12118.64 & 0.000 & 0.000 & 2129489594 & $0.000-$ \\
\hline \multicolumn{6}{|c|}{ Gender } \\
\hline$B$ & SE & Wald & $p$ value & OR & $95 \% \mathrm{Cl}$ \\
\hline-1.06 & 0.4 & 7.11 & 0.01 & 0.35 & $0.158-0.754$ \\
\hline \multicolumn{6}{|c|}{ Age } \\
\hline$B$ & SE & Wald & $p$ value & OR & $95 \% \mathrm{Cl}$ \\
\hline 0.09 & 0.1 & 0.73 & 0.39 & 1.09 & $0.894-1.332$ \\
\hline \multicolumn{6}{|c|}{ SES } \\
\hline$B$ & SE & Wald & p value & OR & $95 \% \mathrm{Cl}$ \\
\hline-0.5 & 0.31 & 2.56 & 0.110 & 0.61 & $0.330-1.119$ \\
\hline \multicolumn{6}{|c|}{$\mathrm{FSIQ}$} \\
\hline B & SE & Wald & $p$ value & OR & $95 \% \mathrm{Cl}$ \\
\hline-0.07 & 0.02 & 10.9 & 0 & 0.93 & 00.892-0.971 \\
\hline \multicolumn{6}{|c|}{ Gene $\times$ Environment(E) } \\
\hline B & SE & Wald & $p$ value & OR & $95 \% \mathrm{Cl}$ \\
\hline 20.86 & 13894.65 & 0.000 & 0.000 & 1142607181 & 0.000 \\
\hline
\end{tabular}

note: $\mathrm{B}=$ unstandardized partial regression coefficient, $\mathrm{SE}=$ standard error, $\mathrm{OR}=$ odds ratio, Wald $=(\mathrm{SE} / \mathrm{B}) 2, \mathrm{Cl}=$ confidence interval. Dependent variable is existence of diagnosis $(0=$ no, 1 = childhood depression).

Independent variables: 5 -HTTLPR genotype $(0=s / s, 1=s / l, 2=l / l)$, Adversity (maternal depression: $0=$ no, $1=$ yes). Gender $(0=$ female, $1=$ male), SES (from $0=$ low income to $5=$ high income). 
Table 4 Multivariable logistic regression analyses using stepwise procedure

\begin{tabular}{|c|c|c|c|c|c|c|}
\hline \multicolumn{7}{|c|}{ Model1 } \\
\hline & B & SE & Wald & $p$ value & OR & $95 \% \mathrm{Cl}$ \\
\hline$G \times E$ interaction & -1.39 & 25254.67 & 0.000 & 1.000 & 0.25 & $0.000-$ \\
\hline Genotype (G) & -1.54 & 0.98 & 2.447 & 0.12 & 0.22 & $0.031-1.475$ \\
\hline Adversity (E) & 21.04 & 21970.77 & 0.000 & 1 & 1371627685 & $0.000-$ \\
\hline Gender & 23.7 & 6397.2 & 0.000 & 1 & 0.000 & $0.000-$ \\
\hline Age & 0.1 & 0.234 & 0.18 & 0.67 & 1.1 & $0.697-1.747$ \\
\hline SES & -1.64 & 0.77 & 0.000 & 1 & 1371627685 & $0.000-$ \\
\hline FSIQ & -0.79 & 0.39 & 4.057 & 0.04 & 0.92 & $0.855-0.998$ \\
\hline \multicolumn{7}{|c|}{ Fit index of this model: $x 2=61.216(p<0.001),-2 \log$ likelihood $=37.706$, discriminate accuracy $=96.9 \%$} \\
\hline \multicolumn{7}{|c|}{ Model2 } \\
\hline & B & SE & Wald & $p$ value & OR & $95 \% \mathrm{Cl}$ \\
\hline Genotype (G) & -1.54 & 0.98 & 2.447 & 0.12 & 0.22 & $0.031-1.175$ \\
\hline Adversity (E) & 20.21 & 10910.59 & 0.000 & 1 & 599809518 & $0.000-$ \\
\hline Gender & -23.7 & 6393.91 & 0 & 1 & 0.000 & $0.000-$ \\
\hline Age & 0.1 & 0.23 & 0.18 & 0.67 & 1.1 & $0.697-1.747$ \\
\hline SES & -1.64 & 0.77 & 4.567 & 0.03 & 0.2 & $0.043-0.873$ \\
\hline FSIQ & -0.08 & 0.04 & 4.06 & 0.04 & 0.92 & $0.855-0.998$ \\
\hline
\end{tabular}

Fit index of this model: $x 2=61.216(p<0.001)$, $-2 \log$ likelihood $=37.706$, discriminate accuracy $=96.9 \%$

\begin{tabular}{|c|c|c|c|c|c|c|}
\hline \multicolumn{7}{|c|}{ Model3 } \\
\hline & B & SE & Wald & $p$ value & OR & $95 \% \mathrm{Cl}$ \\
\hline Gender & -22.31 & 7045.95 & 0 & 1 & 0 & 0.000 \\
\hline FSIQ & -0.088 & 0.04 & 6.08 & 0.01 & 0.92 & $0.853-0.982$ \\
\hline
\end{tabular}

Fit index of this model: $x 2=50.660(p<0.001)$, -2 log likelihood $=48.262$, discriminate accuracy $=96.9 \%$

note: $\mathrm{B}=$ unstandardized partial regression coefficient, $\mathrm{SE}=$ standard error, $\mathrm{OR}=$ odds ratio, Wald $=(\mathrm{SE} / \mathrm{B}) 2, \mathrm{Cl}=$ confidence interval . dependent variable is existence of diagnosis ( $0=$ no, $1=$ childhood depression). Independent variables: 5 -HTTLPR genotype $(0=s / s, 1=s / l, 2=I / l)$, Adversity (maternal depression: $0=$ no, $1=$ yes). Gender $(0=$ female, $1=$ male), SES(from $0=$ low income to $5=$ high income).

Early life stress is a risk factor for major depression, posttraumatic stress disorder (PTSD), and drug abuse, among other conditions $[8,41]$. In recent years, a possible association of the 5-HTTLPR with youth depression has been traced in numerous studies [42-54]. Most studies were based on Caucasian populations, except for a few examining the Japanese general population $[55,56]$. No significant

Table 5 Two-way analysis of variance for investigating the main effect and $G \times E$ interaction

\begin{tabular}{lccc}
\hline & $\begin{array}{c}\text { Type III sum } \\
\text { of squares }\end{array}$ & F value & P value \\
\hline genotype $(G)$ & 47.884 & .302 & .740 \\
adversity $(E)$ & 7.175 & .091 & .764 \\
gender & 163.720 & 2.066 & .154 \\
genotype $(G) \times$ adversity (E) & 117.151 & .739 & .480 \\
genotype $(G) \times$ gender & 82.514 & .521 & .596 \\
adversity $(G) \times$ gender & 2.451 & .031 & .861 \\
\hline
\end{tabular}

Dependent variable is Birleson score.

$R 2=0.98$ (adjusted $R 2=0.10$ )

note: $R$ = coefficient of determination, age and gender as covariates. genotypic association of the 5-HTTLPR polymorphism with depression in a Japanese pediatric population, particularly in patients who have adverse parental environment, was operationalized as the mothers' history of recurrent major depressive disorder. This report is the first of genotypic association of the 5-HTTLPR polymorphism in a Japanese pediatric population. Particularly, this study examined the interactive effect of $5-H T T L P R$ and history of maternal depression among children and early adolescents with and without current depression. Moreover, few reports in the literature describe studies of $\mathrm{G} \times \mathrm{E}$ interaction in a sample of young people.

According to logistic regression analyses, our findings suggest that adversity (maternal depression), gender, and FSIQ had a main effect on current depression. Among them, adversity markedly affected the diagnosis of depression. However interpretation of the effect of FSIQ required careful consideration. A low score of FSIQ might be a cause and an effect [57]. More importantly, although G (genotype) $\times \mathrm{E}$ interaction showed a significant main effect on the diagnosis of depression, it might explain the marked 
impact of maternal depression mediating the existence of diagnosis. Therefore, no interaction was found between the genotype and environmental factors in this case.

Additionally, no significant effect of $\mathrm{G} \times \mathrm{E}$ interaction was found with influences of adversity, gender, FSIQ, and age using multivariable logistic regression analyses. Our findings suggest that depression at an early age was mediated mainly by direct family adversity and gender. These results resemble findings reported previously in longitudinal studies $[41,58,59]$.

Numerous behavioral genetics studies have yielded scientific knowledge related to interaction between genes and the environment [60]. Most importantly, interactive effects of genes and environmental factors are expected to appear cumulatively over a long period, suggesting that onset of depression results from long-term exposure to stressors. Therefore, an effect of $\mathrm{G} \times \mathrm{E}$ interaction might not be confirmed in this study because the sample comprised children and early adolescents. Our findings from models 1-3 and two-way ANOVA were in concordance with results from prior studies $[23,61,62]$.

Meta-analyses of the 5-HTTLPR $\mathrm{G} \times \mathrm{E}$ hypothesis have been described in many reports [17,22-24,63-65]. Sample age and gender composition emerge as important factors [64]. Furthermore, the $\mathrm{S}$ allele of 5-HTTLPR has been implicated in the pathology of several neuropsychiatric phenotypes including mood and anxiety disorders $[66,67]$ and in psychiatric disorders that involve serotonergic dysfunction $[68,69]$. Furthermore, we reported previously that sensitive periods exist, during which brain structures are most susceptible to exposure to early life events such as childhood maltreatment. These sensitive periods tend to correspond to times of rapid developmental change [70,71]. Therefore, we emphasize that continued monitoring is recommended for children who have early life stress as they pass through puberty. Reasons for the time lag between early life stress and depression are proposed along with potential strategies for early intervention [72].

Some limitations of this study and its results should be explained. First are the small number of participants and poor statistical power. Second, the covered environmental risk factors in the study were limited. Third, this was not a longitudinal study; no information related to outcomes in late adolescence is available for patients and $\mathrm{HC}$ groups. Fourth, the HC group significantly had high IQ than patient group, suggesting difficulty in case control. Fifth, female predominance was found in the patient group (Fisher exact, $P=0.008$ ), which might influence the findings. Given these limitations, it will be important for future studies to ensure an adequate range of environmental variables and populations studied because a restricted range can strongly influence $\mathrm{G} \times \mathrm{E}$ results. Furthermore, to tease apart and thereby discern the respective influences of $\mathrm{G} \times \mathrm{E}, \mathrm{G} \times \mathrm{G}$, and $\mathrm{E} \times \mathrm{E}$ interactions, employing a molecular framework to extend this research would be beneficial. A follow-up study using both molecular genetics methods and measures of proximal environments is expected to provide a useful extension of the current study.

\section{Conclusions}

In a Japanese pediatric sample, we examined whether adverse parental environment, operationalized as a mother's history of recurrent major depressive disorder, interacts with 5-HTTLPR polymorphism to predict a patient's symptoms of depression. Data obtained from children and adolescents who had been carefully diagnosed categorically and data from age-matched controls were analyzed using logistic regression to assess $\mathrm{G} \times \mathrm{E}$ interaction. Despite an equivocal interaction effect, adversity and gender showed a significant main effect.

\section{Abbreviations}

( $\mathrm{G} \times \mathrm{E})$ : Gene-by-environment; (5-HTTLPR): Serotonin-transporter-linked polymorphic region; (S): Short allele; (L): Long allele; (DSM-IV-TR): Diagnostic and Statistical Manual of Mental Disorders, Fourth Edition, Text Revision; (SD): Standard deviation; (SCID): Structured Clinical Interview for DSM-IV; (HC): Healthy controls; (ADHD): Attention deficit hyperactivity disorder; (SDS): Zung self-rating depression scale; (DSRS-C): Birleson Depression SelfRating Scale for Children; (WISC-III): Wechsler Intelligence Scale for Children Third Edition; (CBCL-YSR): Child Behavior Checklist Youth Self-Report; (SES): Socioeconomic status; (PCR): Polymerase chain reaction; (ANCOVA): Analysis of covariance; (ANOVA): Analysis of variance; (FSIQ): Fullscale IQ; (VIQ): Verbal IQ; (PIQ): Performance IQ; (PTSD): Post-traumatic stress disorder.

\section{Competing interests}

The authors reported no biomedical financial interests or potential conflicts of interest. The authors have declared that no competing interests exist.

\section{Authors' contributions}

All authors have contributed to the manuscript as described below: AT designed and supervised the whole study, and AT and JK recruited and assessed the eligible patients with interviews and neuropsychological evaluation. TT and MO collected healthy control blood samples. SN, TXF, and KS conducted genotyping. Statistical analyses were conducted by AT and $\mathrm{NM}$. The manuscript was originally written by AT and was revised by NM. However, all authors assisted in the revision process. All authors read and approved the final manuscript.

\section{Acknowledgements}

We would like to thank Tomoko Yamaguchi, MA, for her excellent technical assistance in recruiting participants.

\section{Funding}

This work was supported by a Grant-in-Aid for Scientific Research (B) and Challenging Exploratory Research from the Ministry of Education, Culture, Sports, Science and Technology (MEXT) of Japan (KAKENHI: grant number 24300149 and 23650223 to A.T.). This work also was partially supported by a Grant-in-Aid for Scientific Research from Japan-U.S. Brain Research Cooperation Program (grant number 210201 to AT), as well as the Research Grants from the University of Fukui to AT.

The funding organizations had no role in the design and conduct of the study; collection, management, analysis, and interpretation of the data; and preparation, review, or approval of the manuscript.

\section{Author details}

'Research Center for Child Mental Development, University of Fukui, Fukui, Japan. ${ }^{2}$ Department of Neurobiology\& Behavior Unit of Basic Medical Sciences Course of Medical \& Dental Sciences, Nagasaki University Graduate School of Biomedical Sciences, Nagasaki, Japan. ${ }^{3}$ School of Education, Tokyo 
University and Graduate School of Social Welfare, Tokyo, Japan. ${ }^{4}$ Department of Child Development, Faculty of Life Sciences, Kumamoto University, Kumamoto, Japan.

Received: 25 January 2013 Accepted: 16 April 2013

Published: 10 May 2013

\section{References}

1. American Psychiatric Association: Diagnostic and Statistical Manual of Mental Disorders, Fourth Edition. 4th edition. Washington, D.C.: American Psychiatric Press; 1994.

2. Association AP: Diagnostic and Statistical Manual of Mental Disorders, 4th ed., Text Revision (DSM-IV-TR). Washington, DC: American Psychiatric Association; 2000.

3. Verhulst FC, van der Ende J, Ferdinand RF, Kasius MC: The prevalence of DSM-III-R diagnoses in a national sample of Dutch adolescents. Arch Gen Psychiatr 1997, 54(4):329-336.

4. Birmaher B, Ryan ND, Williamson DE, Brent DA, Kaufman J, Dahl RE, Perel J, Nelson B: Childhood and adolescent depression: a review of the past 10 years. Part I. J Am Acad Child Adolesc Psychiatry 1996, 35(11):1427-1439.

5. Shaffer D, Gould MS, Fisher P, Trautman P, Moreau D, Kleinman M, Flory M: Psychiatric diagnosis in child and adolescent suicide. Arch Gen Psychiatr 1996, 53(4):339-348

6. Garrison $\mathrm{CZ}$, Waller JL, Cuffe SP, McKeown RE, Addy $\mathrm{CL}$, Jackson $\mathrm{KL}$ : Incidence of major depressive disorder and dysthymia in young adolescents. J Am Acad Child Adolesc Psychiatr 1997, 36(4):458-465.

7. Reynolds M, Brewin CR, Saxton M: Emotional disclosure in school children. J Child Psychol Psychiatr 2000, 41(2):151-159.

8. Bhatia SK, Bhatia SC: Childhood and adolescent depression. Am Fam Physician 2007, 75(1):73-80.

9. Lesch KP: Gene-environment interaction and the genetics of depression J Psychiatr Neurosci 2004, 29(3):174-184.

10. Akil H: Stressed and depressed. Nat Med 2005, 11(2):116-118.

11. Hamet P, Tremblay J: Genetics and genomics of depression. Metabolism 2005, 54(5 Suppl 1):10-15.

12. Kendler KS, Kuhn JW, Vittum J, Prescott CA, Riley B: The interaction of stressful life events and a serotonin transporter polymorphism in the prediction of episodes of major depression: a replication. Arch Gen Psychiatr 2005, 62(5):529-535.

13. Shalev I, Moffitt TE, Sugden K, Williams B, Houts RM, Danese A, Mill J, Arseneault $L$, Caspi A: Exposure to violence during childhood is associated with telomere erosion from 5 to 10 years of age: a longitudinal study. Mol Psychiatr 2013, 18(5):576-581.

14. Caspi A, Sugden K, Moffitt TE, Taylor A, Craig IW, Harrington H, McClay J, Mill J, Martin J, Braithwaite A, et al: Influence of life stress on depression: moderation by a polymorphism in the 5-HTT gene. Science 2003, 301(5631):386-389

15. Stein MB, Schork NJ, Gelernter J: Gene-by-environment (serotonin transporter and childhood maltreatment) interaction for anxiety sensitivity, an intermediate phenotype for anxiety disorders. Neuropsychopharmacology 2008, 33(2):312-319

16. Alexander N, Kuepper Y, Schmitz A, Osinsky R, Kozyra E, Hennig J: Geneenvironment interactions predict cortisol responses after acute stress: implications for the etiology of depression. Psychoneuroendocrinology 2009, 34(9):1294-1303.

17. Caspi A, Hariri AR, Holmes A, Uher R, Moffitt TE: Genetic sensitivity to the environment: the case of the serotonin transporter gene and its implications for studying complex diseases and traits. Am J Psychiatr 2010, 167(5):509-527.

18. Mueller A, Armbruster D, Moser DA, Canli T, Lesch KP, Brocke B, Kirschbaum $C$ : Interaction of serotonin transporter gene-linked polymorphic region and stressful life events predicts cortisol stress response. Neuropsychopharmacology 2011, 36(7):1332-1339.

19. Klucken T, Alexander N, Schweckendiek J, Merz CJ, Kagerer S, Osinsky R, Walter B, Vaitl D, Hennig J, Stark R: Individual differences in neural correlates of fear conditioning as a function of 5-HTTLPR and stressful life events. Soc Cogn Affect Neurosci 2013, 8(3):318-325.

20. Kaufman J, Yang BZ, Douglas-Palumberi H, Grasso D, Lipschitz D, Houshyar S, Krystal JH, Gelernter J: Brain-derived neurotrophic factor-5-HTTLPR gene interactions and environmental modifiers of depression in children. Biol Psychiatr 2006, 59(8):673-680.
21. Nederhof E, Bouma EM, Oldehinkel AJ, Ormel J: Interaction between childhood adversity, brain-derived neurotrophic factor val/met and serotonin transporter promoter polymorphism on depression: the TRAILS study. Biol Psychiatr 2010, 68(2):209-212.

22. Karg K, Burmeister M, Shedden K, Sen S: The serotonin transporter promoter variant (5-HTTLPR), stress, and depression meta-analysis revisited: evidence of genetic moderation. Arch Gen Psychiatr 2011, 68(5):444-454.

23. Risch N, Herrell R, Lehner T, Liang KY, Eaves L, Hoh J, Griem A, Kovacs M, Ott J, Merikangas KR: Interaction between the serotonin transporter gene (5-HTTLPR), stressful life events, and risk of depression: a meta-analysis. JAMA 2009, 301(23):2462-2471.

24. Munafo MR, Durrant C, Lewis G, Flint J: Gene X environment interactions at the serotonin transporter locus. Biol Psychiatr 2009, 65(3):211-219.

25. Zung WW: A Self-Rating Depression Scale. Arch Gen Psychiatr 1965, 12:63-70.

26. Birleson P: The validity of depressive disorder in childhood and the development of a self-rating scale: a research report. $J$ Child Psychol Psychiatr 1981, 22(1):73-88.

27. Tomoda A, Mizuno K, Murayama N, Joudoi T, Igasaki T, Miyazaki M, Miike T: Event-Related Potentials in Japanese Childhood Chronic Fatigue Syndrome (CCFS). J Pediatr Neurol 2007, 5:199-208.

28. Wechsler D: Manual for the Wechsler Intelligence Scale for Children-Third edition. San Antonio, TX: The Psychological Corporation; 1991.

29. Achenbach TM: Integrative Guide to the 1991 CBCL/4-18, YSR, and TRF Profiles. Burlington: University of Vermont, Department of Psychology; 1991.

30. Tomoda A, Kinoshita S, Korenaga Y, Mabe H: Pseudohypacusis in childhood and adolescence is associated with increased gray matter volume in the medial frontal gyrus and superior temporal gyrus. Cortex 2012, 48(4):492-503.

31. Hollingshead AB: Hollingshead two factor index of social position, occupational categories. Rockville, MD: National Institute of Health, Psychopharmacology Research Branch; 1965

32. Hollingshead AB, Redlich FC: Social class and mental illness: a community study. 1958. Am J Publ Health 2007, 97(10):1756-1757.

33. Nishikawa S, Nishitani S, Fujisawa TX, Noborimoto I, Kitahara T, Takamura T, Shinohara K: Perceived parental rejection mediates the influence of serotonin transporter gene (5-HTTLPR) polymorphisms on impulsivity in Japanese adults. PLoS One 2012, 7(10):e47608.

34. Obayashi K, Olsson M, Anan I, Ueda M, Nakamura M, Okamoto S, Yamashita T, Miida T, Ando Y, Suhr OB: Impact of serotonin transporter and catecholO-methyl transferase genes polymorphism on gastrointestinal dysfunction in Swedish and Japanese familial amyloidotic polyneuropathy patients. Clin Chim Acta Int J Clin Chem 2008, 398(1-2):10-14.

35. Toyoshima F, Oshima T, Nakajima S, Sakurai J, Tanaka J, Tomita T, Hori K, Matsumoto T, Miwa H: Serotonin transporter gene polymorphism may be associated with functional dyspepsia in a Japanese population. BMC Med Genet 2011, 12:88.

36. Gelernter J, Kranzler H, Cubells JF: Serotonin transporter protein (SLC6A4) allele and haplotype frequencies and linkage disequilibria in African- and European-American and Japanese populations and in alcohol-dependent subjects. Hum Genet 1997, 101(2):243-246.

37. Willeit M, Praschak-Rieder N, Neumeister A, Zill P, Leisch F, Stastny J, Hilger E, Thierry N, Konstantinidis A, Winkler D, et al: A polymorphism (5-HTTLPR) in the serotonin transporter promoter gene is associated with DSM-IV depression subtypes in seasonal affective disorder. Mol Psychiatr 2003, 8(11):942-946

38. Kazdin AE: Childhood depression. J Child Psychol Psychiatr 1990, 31(1):121-160

39. Hasin DS, Goodwin RD, Stinson FS, Grant BF: Epidemiology of major depressive disorder: results from the National Epidemiologic Survey on Alcoholism and Related Conditions. Arch Gen Psychiatr 2005, 62(10):1097-1106.

40. Teicher MH, Vitaliano GD: Witnessing violence toward siblings: an understudied but potent form of early adversity. PLoS One 2011, 6(12):e28852.

41. Schilling EA, Aseltine RH Jr, Gore S: Adverse childhood experiences and mental health in young adults: a longitudinal survey. BMC Publ Health 2007, 7:30.

42. Aguilera M, Arias B, Wichers M, Barrantes-Vidal N, Moya J, Villa H, van Os J, Ibanez MI, Ruiperez MA, Ortet G, et al: Early adversity and 5-HTT/BDNF genes: new evidence of gene-environment interactions on depressive symptoms in a general population. Psychol Med 2009, 39(9):1425-1432.

43. Araya R, Hu X, Heron J, Enoch MA, Evans J, Lewis G, Nutt D, Goldman D: Effects of stressful life events, maternal depression and 5-HTTLPR 
genotype on emotional symptoms in pre-adolescent children. Am J Med Genet B Neuropsychiatr Genet 2009, 150B(5):670-682.

44. Blakely RD, Veenstra-VanderWeele J: Genetic indeterminism, the 5-HTTLPR, and the paths forward in neuropsychiatric genetics. Arch Gen Psychiatr 2011, 68(5):457-458.

45. Brown GW, Harris TO: Depression and the serotonin transporter 5-HTTLPR polymorphism: a review and a hypothesis concerning gene-environment interaction. J Affect Disord 2008, 111(1):1-12.

46. Chen MC, Joormann J, Hallmayer J, Gotlib $\mathrm{H}$ : Serotonin transporter polymorphism predicts waking cortisol in young girls.

Psychoneuroendocrinology 2009, 34(5):681-686.

47. Cicchetti D, Rogosch FA, Oshri A: Interactive effects of corticotropin releasing hormone receptor 1 , serotonin transporter linked polymorphic region, and child maltreatment on diurnal cortisol regulation and internalizing symptomatology. Dev Psychopathol 2011, 23(4):1125-1138.

48. Cicchetti D, Rogosch FA, Sturge-Apple M, Toth SL: Interaction of child maltreatment and 5-HTT polymorphisms: suicidal ideation among children from low-SES backgrounds. J Pediatr Psychol 2010, 35(5):536-546.

49. Frodl T, Reinhold E, Koutsouleris N, Donohoe G, Bondy B, Reiser M, Moller $H J$, Meisenzahl EM: Childhood stress, serotonin transporter gene and brain structures in major depression. Neuropsychopharmacology 2010, 35(6):1383-1390.

50. Furman DJ, Hamilton JP, Joormann J, Gotlib $I \mathrm{H}$ : Altered timing of amygdala activation during sad mood elaboration as a function of 5-HTTLPR. Soc Cogn Affect Neurosci 2011, 6(3):270-276.

51. Gibb BE, Benas JS, Grassia M, McGeary J: Children's attentional biases and 5-HTTLPR genotype: potential mechanisms linking mother and child depression. J Clin Child Adolesc Psychol 2009, 38(3):415-426.

52. Gibb BE, Grassia M, Stone LB, Uhrlass DJ, McGeary JE: Brooding rumination and risk for depressive disorders in children of depressed mothers. J Abnorm Child Psychol 2012, 40(2):317-326.

53. Gibb BE, Uhrlass DJ, Grassia M, Benas JS, McGeary J: Children's inferential styles, 5-HTTLPR genotype, and maternal expressed emotion-criticism: An integrated model for the intergenerational transmission of depression. J Abnorm Psychol 2009, 118(4):734-745.

54. Goodyer IM, Bacon A, Ban M, Croudace T, Herbert J: Serotonin transporter genotype, morning cortisol and subsequent depression in adolescents. Br J Psychiatr 2009, 195(1):39-45.

55. Ezaki N, Nakamura K, Sekine Y, Thanseem I, Anitha A, Iwata Y, Kawai M, Takebayashi K, Suzuki K, Takei N, et al: Short allele of 5-HTTLPR as a risk factor for the development of psychosis in Japanese methamphetamine abusers. Ann N Y Acad Sci 2008, 1139:49-56.

56. Ohira H, Matsunaga M, Isowa T, Nomura M, Ichikawa N, Kimura K, Kanayama $\mathrm{N}$, Murakami H, Osumi T, Konagaya T, et al: Polymorphism of the serotonin transporter gene modulates brain and physiological responses to acute stress in Japanese men. Stress 2009, 12(6):533-543.

57. Staton RD, Wilson H, Brumback RA: Cognitive improvement associated with tricyclic antidepressant treatment of childhood major depressive illness. Percept Mot Skills 1981, 53(1):219-234.

58. Engert V, Efanov SI, Dedovic K, Duchesne A, Dagher A, Pruessner JC: Perceived early-life maternal care and the cortisol response to repeated psychosocial stress. J Psychiatr Neurosci 2010, 35(6):370-377.

59. Zwierzynska K, Wolke D, Lereya TS: Peer Victimization in Childhood and Internalizing Problems in. A Prospective Longitudinal Study. J Abnorm Child Psychol: Adolescence; 2012.

60. Caspi A, Moffitt TE, Morgan J, Rutter M, Taylor A, Arseneault L, Tully L, Jacobs C, Kim-Cohen J, Polo-Tomas M: Maternal expressed emotion predicts children's antisocial behavior problems: using monozygotic-twin differences to identify environmental effects on behavioral development. Dev Psychol 2004, 40(2):149-161.

61. Chipman $P$, Jorm AF, Tan $X Y$, Easteal S: No association between the serotonin-1A receptor gene single nucleotide polymorphism rs6295C/G and symptoms of anxiety or depression, and no interaction between the polymorphism and environmental stressors of childhood anxiety or recent stressful life events on anxiety or depression. Psychiatr Genet 2010, 20(1):8-13.

62. Middeldorp CM, de Geus EJ, Willemsen G, Hottenga JJ, Slagboom PE, Boomsma DI: The serotonin transporter gene length polymorphism (5-HTTLPR) and life events: no evidence for an interaction effect on neuroticism and anxious depressive symptoms. Twin Res Hum Genet 2010, 13(6):544-549.
63. Uher R: The implications of gene-environment interactions in depression: will cause inform cure? Mol Psychiatr 2008, 13(12):1070-1078.

64. Uher R, McGuffin P: The moderation by the serotonin transporter gene of environmental adversity in the aetiology of mental illness: review and methodological analysis. Mol Psychiatr 2008, 13(2):131-146.

65. Kaufman J, Gelernter J, Kaffman A, Caspi A, Moffitt T: Arguable assumptions, debatable conclusions. Biol Psychiatr 2010, 67(4):e19-20. author reply e21-13.

66. Schinka JA, Busch RM, Robichaux-Keene N: A meta-analysis of the association between the serotonin transporter gene polymorphism (5-HTTLPR) and trait anxiety. Mol Psychiatr 2004, 9(2):197-202.

67. Sen S, Burmeister M, Ghosh D: Meta-analysis of the association between a serotonin transporter promoter polymorphism (5-HTTLPR) and anxietyrelated personality traits. Am J Med Genet B Neuropsychiatr Genet 2004, 127B(1):85-89.

68. Lotrich FE, Pollock BG: Meta-analysis of serotonin transporter polymorphisms and affective disorders. Psychiatr Genet 2004, 14(3):121-129.

69. Lasky-Su JA, Faraone SV, Glatt SJ, Tsuang MT: Meta-analysis of the association between two polymorphisms in the serotonin transporter gene and affective disorders. Am J Med Genet B Neuropsychiatr Genet 2005, 133B(1):110-115.

70. Andersen SL, Tomoda A, Vincow ES, Valente E, Polcari A, Teicher MH: Preliminary evidence for sensitive periods in the effect of childhood sexual abuse on regional brain development. J Neuropsychiatry Clin Neurosci 2008, 20(3):292-301.

71. Tomoda A, Navalta CP, Polcari A, Sadato N, Teicher MH: Childhood sexual abuse is associated with reduced gray matter volume in visual cortex of young women. Biol Psychiatr 2009, 66(7):642-648.

72. Teicher MH, Samson JA, Polcari A, Andersen SL: Length of time between onset of childhood sexual abuse and emergence of depression in a young adult sample: a retrospective clinical report. J Clin Psychiatr 2009, 70(5):684-691.

doi:10.1186/1471-244X-13-134

Cite this article as: Tomoda et al:: No interaction between serotonin transporter gene (5-HTTLPR) polymorphism and adversity on depression among Japanese children and adolescents. BMC Psychiatry 2013 13:134.

\section{Submit your next manuscript to BioMed Central and take full advantage of:}

- Convenient online submission

- Thorough peer review

- No space constraints or color figure charges

- Immediate publication on acceptance

- Inclusion in PubMed, CAS, Scopus and Google Scholar

- Research which is freely available for redistribution 